\title{
Thermal stability and field assisted sintering of cerium-doped YSZ ceramic nanoparticles obtained via a hydrothermal process
}

\author{
Dumitru V. Dragut ${ }^{1}$, Viorel Badilita ${ }^{1}$, Adrian M. Motoc ${ }^{1}$, Radu R. Piticescu ${ }^{1, *}$, Jie Zhao ${ }^{2}$, Hasan Hijji ${ }^{2}$, and \\ Luca Conte ${ }^{3}$ \\ ${ }^{1}$ National Institute for Nonferrous and Rare Metals - IMNR, Blvd. Biruintei No. 102, Pantelimon, Ilfov, Romania \\ ${ }^{2}$ Centre for Precision Manufacturing, The University of Strathclyde, Glasgow G1 1XJ, UK \\ ${ }^{3}$ MATRES srl, via Armando Diaz 21, 31100 Treviso, Italy
}

Received: 10 April 2017 / Accepted: 5 July 2017

\begin{abstract}
Owing to its extraordinary range of properties, yttria-doped zirconia holds a unique place among the ceramic oxide systems. To improve the properties for some specific custom design applications, co-doping with other rare earth oxides such as ceria is needed. The aim of this paper is to identify the correlations between the phase composition evolution with increasing thermal treatment temperature in order to establish the thermal stability in connection with the ceria content and how does it influence the yttria-stabilised zirconia microstructure. The $\mathrm{ZrO}_{2}-3 \mathrm{Y}_{2} \mathrm{O}_{3}-n \mathrm{CeO}_{2}(n=3,6$ and $9 \mathrm{wt} . \%)$ samples were obtained by a hydrothermal process and submitted to a thermal treatment up to $1600^{\circ} \mathrm{C}$. Intensive characterization was performed via X-ray powder diffraction and EDX analysis. It was found that up to $400^{\circ} \mathrm{C}$, a monophasic structure was formed. At higher temperatures tetragonal zirconia is formed as a major phase with the presence of secondary monoclinic and cubic phases, depending on the Ce content and thermal treatment temperature. Sintered compacts with densities up to $99.5 \%$ from the theoretical density were obtained starting from the $6 \% \mathrm{CeO}_{2}-3 \% \mathrm{Y}_{2} \mathrm{O}_{3}-\mathrm{ZrO}_{2}-$ nanostructured powders using a special field-assisted (FAST) sintering process. With increasing $\mathrm{CeO}_{2}$ content to $9 \%$ only, tetragonal zirconia with 6-9 $\mathrm{nm}$ crystallite sizes is formed during the FAST sintering process.
\end{abstract}

Keywords: zirconia / hydrothermal / thermal stability / agglomerated nanoparticles / field assisted sintering

\section{Introduction}

Hydrothermal method is one of the chemical synthesis methods with high potential for obtaining nanostructured materials with controlled properties. The hydrothermal chemistry is responsible for the formation of many minerals. The successes of the researchers in the hydrothermal synthesis of big quartz piezoelectric mono-crystals have stimulated the development of fundamental studies in the physical-chemical synthesis of hydrothermal solutions. Actually hydrothermal processes may be defined as "reactions occurring under the condition of high temperature and pressures $\left(>100^{\circ} \mathrm{C},>1 \mathrm{~atm}\right)$ in aqueous solutions in a closed system" [1]. The hydrothermal processes used in the synthesis of nanostructured oxides involve hydrothermal reactions using different water soluble precursors, hydrothermal treatment for the purification or structural transformation of materials previously prepared by other methods and hydrothermal growth of the crystals by

* e-mail: rpiticescu@imnr.ro controlling the dissolution - reprecipitation in solutions. The main advantages of the hydrothermal synthesis compared to other synthesis routes [2,3] are as follows: one-step process for powder synthesis or oriented ceramic films; minimised consumption energy; closed-flow system; relatively high deposition rate; products with much higher homogeneity than solid state processing; products with higher density than gas or vacuum processing (faster growth rate): versatility: oxides, non-oxides, organic/ biologic materials, hybrid materials with different morphologies may be obtained. A comparison between different routes for obtaining ceramic powders with controlled composition and morphology is presented in Table 1 [4].

Zirconia $\left(\mathrm{ZrO}_{2}\right)$ is a polymorphic ceramic material with very interesting and useful optical, electrical, thermal, mechanical and biocompatibility properties. Below $1100{ }^{\circ} \mathrm{C}$, monoclinic $(m)$ phase of pure $\mathrm{ZrO}_{2}$ is the stable form. From 1100 up to $2370{ }^{\circ} \mathrm{C}$, pure $\mathrm{ZrO}_{2}$ has a tetragonal structure, but at temperatures between 2370 and $2706{ }^{\circ} \mathrm{C}$ (the melting point), it exists as cubic phase. The stabilisation of high temperature zirconia polymorphs play 
Table 1. Comparison of some ceramic powders synthesis routes.

\begin{tabular}{llllll}
\hline Synthesis route & Solid state process & Co-precipitation & Hydro-thermal & Sol-gel & Spray pyrolysis \\
\hline Composition control & Poor & Good & Excellent & Medium & Excellent \\
Morphology control & Poor & Medium & Good & Medium & Good \\
Particle size (nm) & $>1000$ & $>100$ & $10-100$ & $>10$ & $>10$ \\
Hard agglomerates & Medium & High & Low & Medium & Low \\
Impurities (\%) & $0.5-1$ & Max. 0.5 & Max. 0.5 & $0.1-0.5$ & $0.1-0.5$ \\
Additional steps & Calcination, milling & Calcination, milling & No & Calcination, milling No \\
Scalability & Industrial & Industrial & Demonstration Demonstration & R\&D \\
Environmental impact & High & Moderate & Low & High & Moderate \\
\hline
\end{tabular}

a crucial role in several technological applications such as combustion technology, energy conversion, thermal protection and structural materials. The transition from tetragonal to monoclinic phase is done with a volume increase of about $4 \%$ leading to micro-cracking that drastically affects the mechanical properties. Therefore, the stabilisation of cubic or tetragonal phase on larger temperature ranges is required for safety application. The tetragonal or cubic phase can be stabilised, and the transition temperature may be decreased by doping with additives such as $\mathrm{MgO}, \mathrm{CaO}, \mathrm{Y}_{2} \mathrm{O}_{3}$ and other rare earth oxides. For high temperature applications, zirconia doped with $8 \mathrm{~mol} . \%$ yttria showing stable cubic phase is widely used. For any application requiring high mechanical properties, zirconia doped with $3-4$ mol.\% yttria having mixed cubic and tetragonal phases structure is preferred. The doping elements do affect not only the structural and mechanical properties but also the optical and electrical properties. As an example, small amounts of $\mathrm{Ce}^{4+}$ ions dispersed in the bulk zirconia matrix induce photocatalytic properties depending also on the synthesis method [5]. Zirconia-ceria-yttria powders were studied with a theoretical composition of $\mathrm{Y}_{0.148}\left(\mathrm{Zr}_{1-x} \mathrm{Ce}_{x}\right) 0.852 \mathrm{O}_{2}$, where $x=0,0.1,0.3,0.5,0.7,0.9$ and 1.0. A co-precipitation method followed by calcination was used to prepare the powders. It was shown that heat treatment of the coprecipitated material at $900{ }^{\circ} \mathrm{C}$ leads to the nanocrystalline powders of ceria-zirconia yttria solid solutions with a facecentred cubic fluorite type structure [6].

It has been demonstrated that structural stabilisation can be thermodynamically achieved also by reducing the grain size of the material into the nanometric range but the preparation of bulk materials with high relative densities has proven particularly challenging [7]. Solution synthesis of zirconia nanopowders based on the hydrolysis of alkoxides or several hydrothermal/solvothermal methods has been demonstrated as particularly promising in terms of grain size, degree of agglomeration and purity that could be sintered without significantly changing the phase composition by a field assisted (FAST) process at initial uniaxial pressure $150 \mathrm{MPa}$, with a heating rate of $200{ }^{\circ} \mathrm{C} /$ min up to $900{ }^{\circ} \mathrm{C}$ and final pressure of $700 \mathrm{MPa}$ [8].

In contrast, nanoparticles suffer from many problems related to their surface and thermal stability, shape preservation, handling, assembly in devices, etc. It is, therefore, an important challenge to solve these problems by developing larger particles while nanoscale material properties are preserved. A promising method for designing and fabricating these structures is spraying in which spherical particles can be produced by controlled aggregation [9]. The spray drying of colloidal suspensions produced by hydrothermal soft chemical processes may be, therefore, a powerful route to obtain powders with desired properties for future processing by FAST sintering routes.

The dopants used, as well as the retained hydroxyl groups during the hydrothermal process for obtaining the stabilised zirconia, determine the changes of the crystalline structure, such as lattice parameters variations, unit cell volume variations, the variation of the tetragonality of the stabilised zirconia and morphology [10-12]. This complex phase evolution can be revealed by X-ray diffraction and it offers the possibility to view the evolution of the temperature-induced structural properties, thus, obtaining results upon the stability of the nanometric stabilised zirconia [13-15].

The present paper reports a first attempt of studying the temperature-induced structural modifications of codoped ceria-yttria zirconia during thermal treatment of hydrothermally synthesized nanostructured powder and their potential use in developing sintered products with nearly theoretical density using a field assisted-sintering process.

\section{Experimental procedures}

\subsection{Powder preparation}

Analytical grade zirconium chloride from Sigma Aldrich, as well as yttrium oxide and cerium nitrate hexahydrate from Alfa Aesar were used in the process. The purity of the raw materials was confirmed by a preliminary X-ray diffraction analysis. The samples were obtained via a hydrothermal process performed in a 5 -litter Teflon-linen 5 Berghoff autoclave at $200{ }^{\circ} \mathrm{C}$ for $2 \mathrm{~h}$ using ammonia for complete precipitation of the doped oxide. The synthesis procedure is similar to that described in our previous paper [16] and the temperature and $\mathrm{pH}$ were selected based on these previous results and thermodynamic predictions using HSC Chemistry 8 software, with an initial $\mathrm{Zr}^{4+}$ ionic concentration of $0.1 \mathrm{M}$. While the yttria concentration was maintained constant in every sample at $3 \mathrm{~mol} . \%$, the addition of ceria was set to 3,6 and 9 mol.\%. Figure 1 shows the predicted 


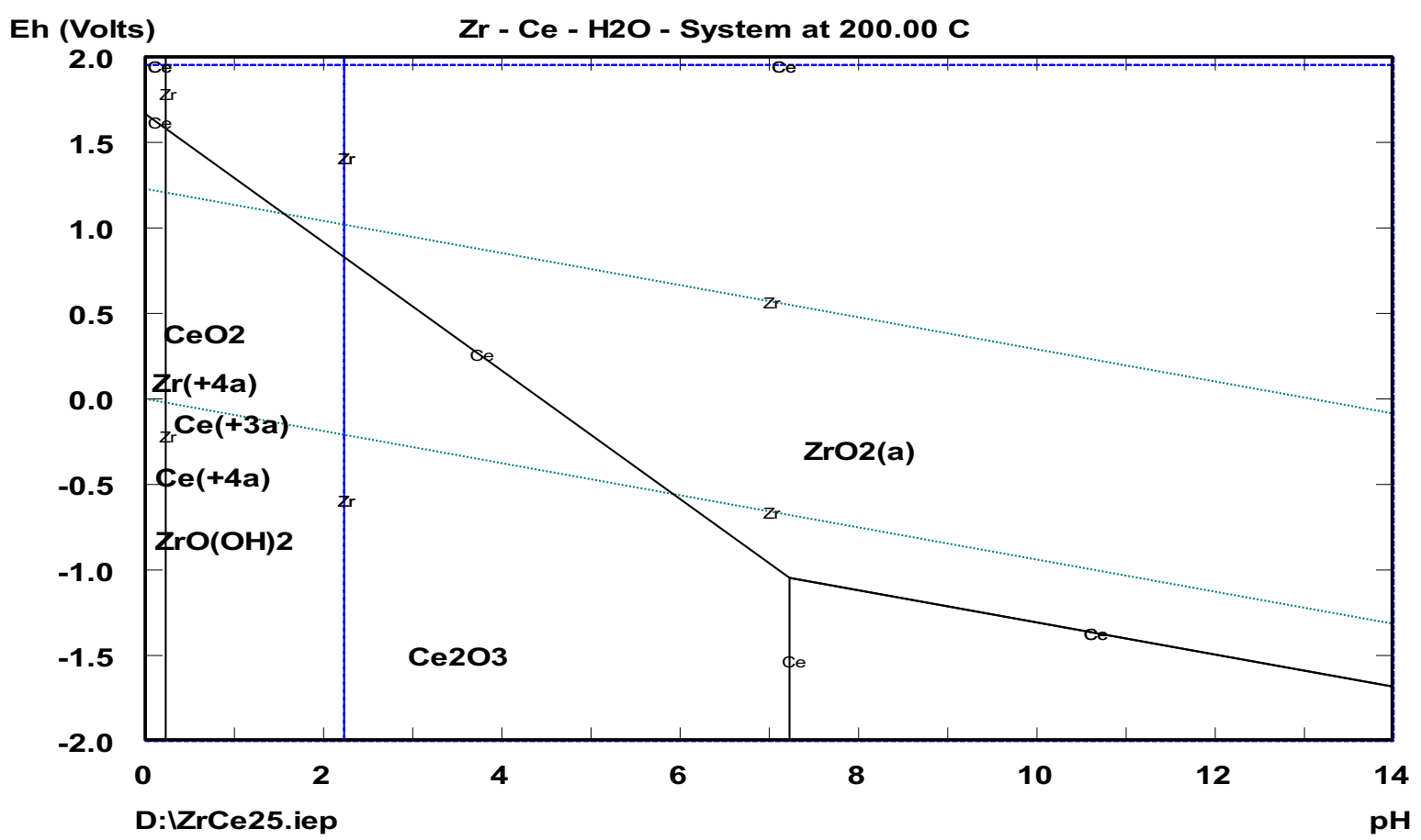

Fig. 1. Pourbaix diagram of $\mathrm{Zr}-\mathrm{Y}-\mathrm{Ce}-\mathrm{H}_{2} \mathrm{O}$ system in hydrothermal solutions at $200^{\circ} \mathrm{C}$.

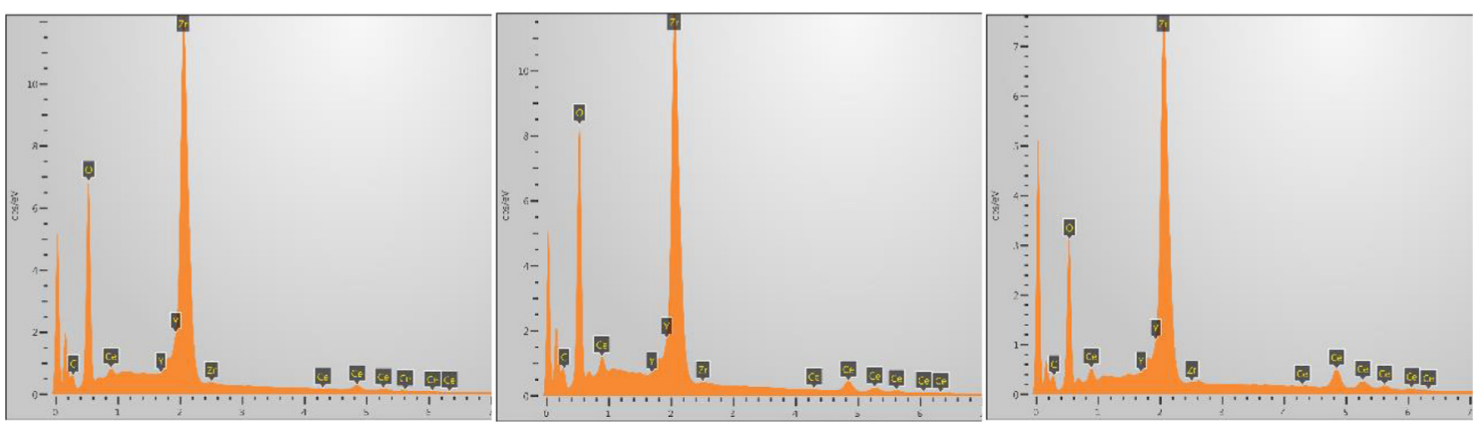

\begin{tabular}{|l|c|c|c|}
\hline & $\mathrm{A}(\mathrm{ZrO} 2-3 \mathrm{Y}-3 \mathrm{Ce})$ & $\mathrm{B}(\mathrm{ZrO} 2-3 \mathrm{Y}-6 \mathrm{Ce})$ & $\mathrm{C}(\mathrm{ZrO} 2-3 \mathrm{Y}-9 \mathrm{Ce})$ \\
\hline Zr at. $\%$ & 87,93 & 83,80 & 76,70 \\
\hline Ce at. $\%$ & 5,67 & 11,29 & 19,31 \\
\hline Y at. $\%$ & 6,40 & 4,91 & 3,99 \\
\hline
\end{tabular}

Fig. 2. EDS analysis results of the $\mathrm{ZrO}_{2}-3 \mathrm{Y}-n \mathrm{Ce}(n=3,6,9)$ samples.

potential-P (Pourbaix) diagram for $\mathrm{Zr}-\mathrm{Y}-\mathrm{Ce}-\mathrm{H}_{2} \mathrm{O}$ system in hydrothermal solutions at $200^{\circ} \mathrm{C}$, showing that a $\mathrm{pH}$ $>7.2$ ensure the optimal co-precipitation conditions for Cedoped $\mathrm{ZrO}_{2}$.

Zirconia powders doped with $3 \mathrm{~mol} . \% \mathrm{Y}_{2} \mathrm{O}_{3}$ and codoped with 3 mol. $\% \quad \mathrm{Y}_{2} \mathrm{O}_{3}-6$ mol. $\% \quad \mathrm{CeO}_{2}$ have been selected for preliminary FAST sintering tests. The hydrothermally synthesized powders after washing with distilled water to remove the synthesis by-products were mixed with a solution containing 6 wt.\% polyvinyl alcohol as binder and spray dried using a LabPlant spray drier system in the same working conditions (air speed of $3.5 \mathrm{~m} / \mathrm{s}$ at evacuation and feeding rate of $617 \mathrm{~mL} / \mathrm{h}$ using a $0.5 \mathrm{~mm}$ nozzle). The agglomeration of nanoparticles was designed to improve powder flowability and eliminate possible inhalation risks during manipulation.
In order to investigate in details the structural transformations that appears upon heating and to study their thermal stability, a set of X-ray diffraction analyses were performed on the as-obtained powders annealed in a Carbolite chamber furnace in air at 400, 800, 1200 and $1600{ }^{\circ} \mathrm{C}$, respectively. All samples were heated with a rate of $20^{\circ} \mathrm{C} / \mathrm{min}$, maintained for $2 \mathrm{~h}$ in alumina crucibles and normally cooled within the furnace.

\subsection{FAST sintering}

FAST (electrical-field-activated sintering technology) sintering tests were carried out using a thermal mechanical simulator - Gleeble 3800, and its fully integrated digital closed-loop control thermal and mechanical testing system makes highly-accurate process control possible. The tests 
Table 2. Comparison between the expected chemical analysis and the results of the EDS analysis.

\begin{tabular}{lll}
\hline & Expected chemical analysis & EDS analysis \\
\hline $\mathrm{ZrO}_{2}-3 \mathrm{Y}-3 \mathrm{Ce}$ & $\left(\mathrm{Zr}_{0.88679} \mathrm{Y}_{0.05660} \mathrm{Ce}_{0.05660}\right) \mathrm{O}_{1.971698}$ & $\sim\left(\mathrm{Zr}_{0.88} \mathrm{Y}_{0.06} \mathrm{Ce}_{0.06}\right) \mathrm{O}_{1.97}$ \\
$\mathrm{ZrO}_{2}-3 \mathrm{Y}-6 \mathrm{Ce}$ & $\left(\mathrm{Zr}_{0.83486} \mathrm{Y}_{0.05505} \mathrm{Ce}_{0.11009}\right) \mathrm{O}_{1.97248}$ & $\sim\left(\mathrm{Zr}_{0.84} \mathrm{Y}_{0.05} \mathrm{Ce}_{0.11}\right) \mathrm{O}_{1.98}$ \\
$\mathrm{ZrO}_{2}-3 \mathrm{Y}-9 \mathrm{Ce}$ & $\left(\mathrm{Zr}_{0.78571} \mathrm{Y}_{0.05357} \mathrm{Ce}_{0.16071}\right) \mathrm{O}_{1.97321}$ & $\sim\left(\mathrm{Zr}_{0.77} \mathrm{Y}_{0.04} \mathrm{Ce}_{0.19}\right) \mathrm{O}_{1.98}$ \\
\hline
\end{tabular}
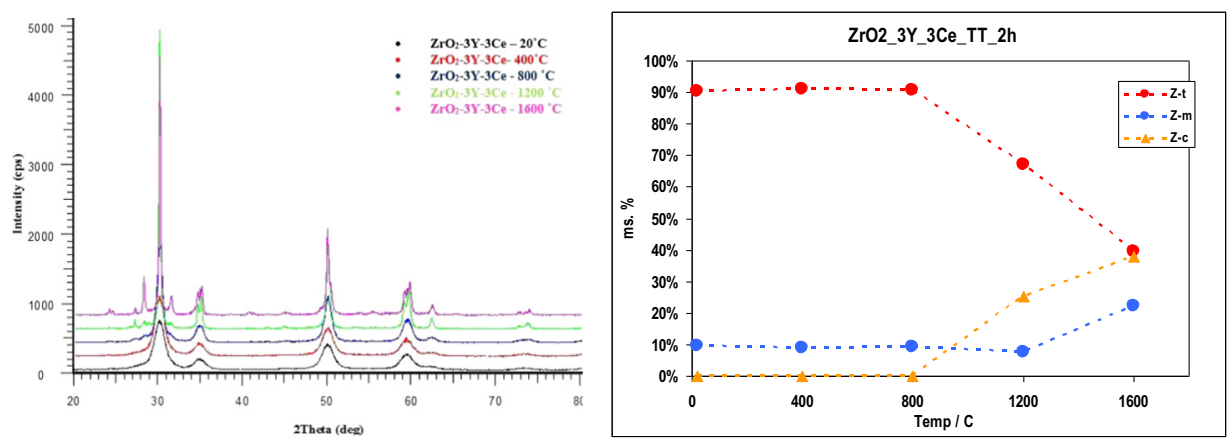

\begin{tabular}{|c|c|c|c|}
\hline Temperature $/{ }^{\circ} \mathbf{C}$ & Monoclinic (\%) & Tetragonal (\%) & Cubic (\%) \\
\hline 20 & 9.60 & 90.40 & - \\
\hline 400 & 9.00 & 91.00 & - \\
\hline 800 & 9.30 & 90.70 & 25.10 \\
\hline 1200 & 7.70 & 67.20 & 38.00 \\
\hline 1600 & 22.40 & 39.70 & \\
\hline
\end{tabular}

Fig. 3. XRD pattern and compositional plotting of $\mathrm{ZrO}_{2}-3 \mathrm{Y}-3 \mathrm{Ce}$ samples.

were conducted with variation of key process-parameters, such as the pressure acting on the die, maximum heatingtemperature and sintering (holding) time. The temperatures from a range of 1100 to $1300^{\circ} \mathrm{C}$ were attempted for sintering, combined with a pressure range of 75.0 to 125.0 MPa and holding time from 120 to $240 \mathrm{~s}$. These were to investigate effects of the process parameters on the densification process as well as part quality formed.

\subsection{Samples characterization}

Rapid analysis by optical micrographs of all investigated samples revealed the presence of rounded particles with sizes ranging from a few microns to tens of microns. According to these investigations increasing the PVA content from 6 to $12 \mathrm{wt}$.\% does not involve any significant modification of the powder morphology and flowability. The same powder morphology was maintained after the heat treatment for $2 \mathrm{~h}$ at $500^{\circ} \mathrm{C}$ to remove the PVA binder and they have been further used in FAST sintering tests.

The chemical composition of the powder samples were investigated with the aid of an electronic microscope Gemini equipped with EDAX while the morphology of spray dried aggregated nanopowders was analysed with a Zeiss system combining optical and electronic microscopy. The samples were sprayed on to a sample holder of the SEM and analysed on multiple spots. The X-ray powder diffraction was performed on a BRUKER D8 ADVANCED Diffractometer, which uses the Bragg-Brentano method, Copper $\mathrm{K} \alpha$ radiation and $\mathrm{SOL} \mathrm{X}$ detector in order to remove Copper $\mathrm{K} \beta$ radiation. Data acquisition and processing was performed with the software DIFFRAC ${ }^{\text {PLUS }}$ Bruker AXS package Release 2006 and ICDD database, Powder Diffraction File, edited by International Centre for Diffraction Data 2006. The obtained data content from XRD diffraction patterns concern information about nature and phase quantities present in samples, crystal structure, lattice parameters, crystallite's size and amorphous content.

The bulk and tap densities of the powders were measured using ASTM D7481-09 and ASTM B527 methods, respectively. The theoretical densities were calculated based on unit cell volume measurements from XRD and the rule of mixtures using the rule of mixtures.

The relative density of the sintered products was calculated based on the ratio between the density measured by Archimede's method and its theoretical skeletal density.

The phase composition of fully dense sintered pellets was also investigated by XRD vs. Ce content, using the same method previously described, after milling the pellets.

\section{Results and discussion}

The EDS analysis results presented in Figure 2 confirm the expected chemical compositions of powders doped with $3 \%$, $6 \%$ and $9 \% \mathrm{Ce}$, respectively. Table 2 presents the corresponding chemical molecular formulas in comparison with the predicted compositions. It is observed a very good agreement between the calculated and experimental compositions within the analysis errors. 

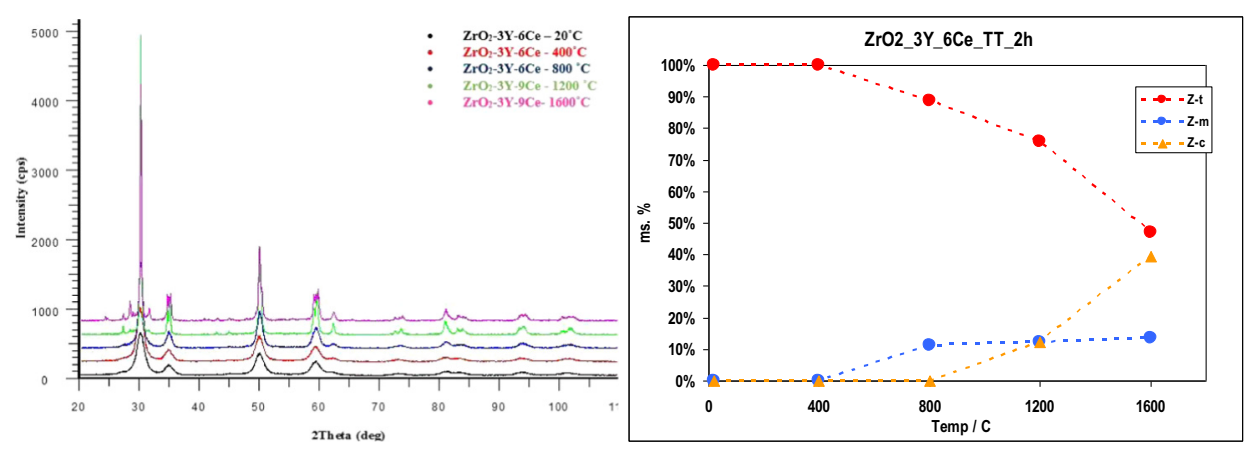

\begin{tabular}{|c|c|c|c|}
\hline Temperature $/{ }^{\circ} \mathbf{C}$ & Monoclinic (\%) & Tetragonal (\%) & Cubic (\%) \\
\hline 20 & - & $100.00 \%$ & - \\
\hline 400 & - & $100.00 \%$ & - \\
\hline 800 & $11.30 \%$ & $88.70 \%$ & - \\
\hline 1200 & $12.20 \%$ & $75.70 \%$ & $12.10 \%$ \\
\hline 1600 & $13.50 \%$ & $47.00 \%$ & $39.50 \%$ \\
\hline
\end{tabular}

Fig. 4. XRD pattern and compositional plotting of $\mathrm{ZrO}_{2}-3 \mathrm{Y}-6 \mathrm{Ce}$ samples.
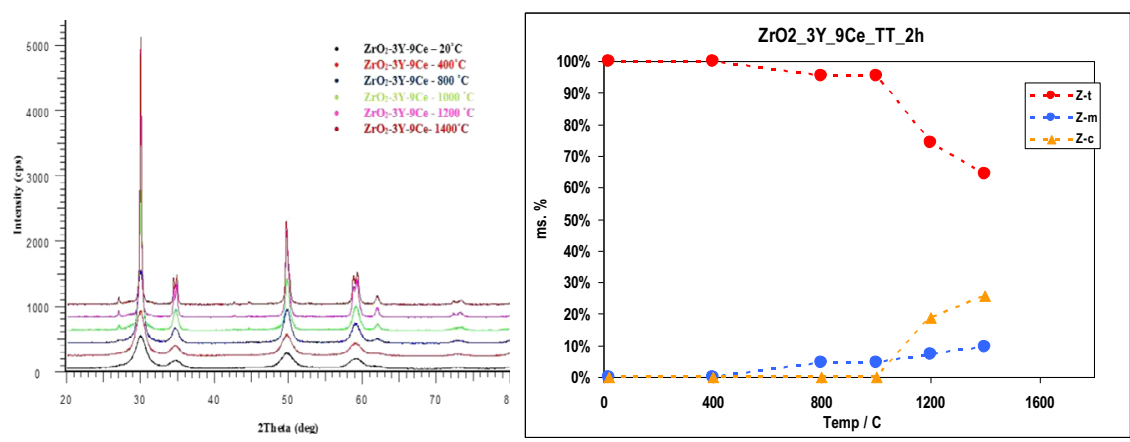

\begin{tabular}{|c|c|c|c|}
\hline Temperature $/{ }^{\circ} \mathbf{C}$ & Monoclinic (\%) & Tetragonal (\%) & Cubic (\%) \\
\hline 20 & 0 & 100 & 0 \\
\hline 400 & 0 & 100 & 0 \\
\hline 800 & 4.70 & 95.30 & 0 \\
\hline 1000 & 4.60 & 95.40 & 0 \\
\hline 1200 & 7.10 & 74.10 & 18.80 \\
\hline 1400 & 9.70 & 64.50 & 25.80 \\
\hline
\end{tabular}

Fig. 5. XRD pattern and compositional plotting of $\mathrm{ZrO}_{2}-3 \mathrm{Y}-9 \mathrm{Ce}$ samples.
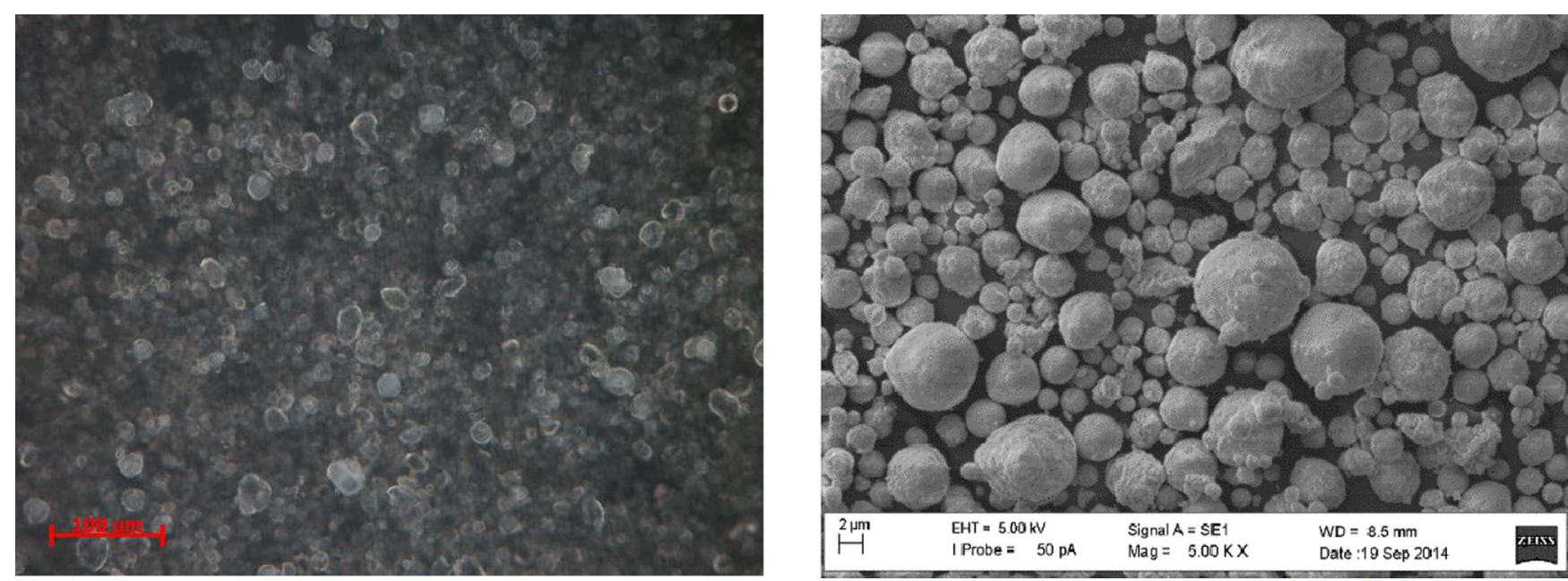

Fig. 6. Optical micrograph (left) and SEM micrograph (right) of $\mathrm{ZrO}_{2}-3 \mathrm{Y}-6 \mathrm{Ce}$ spray dried powders. 

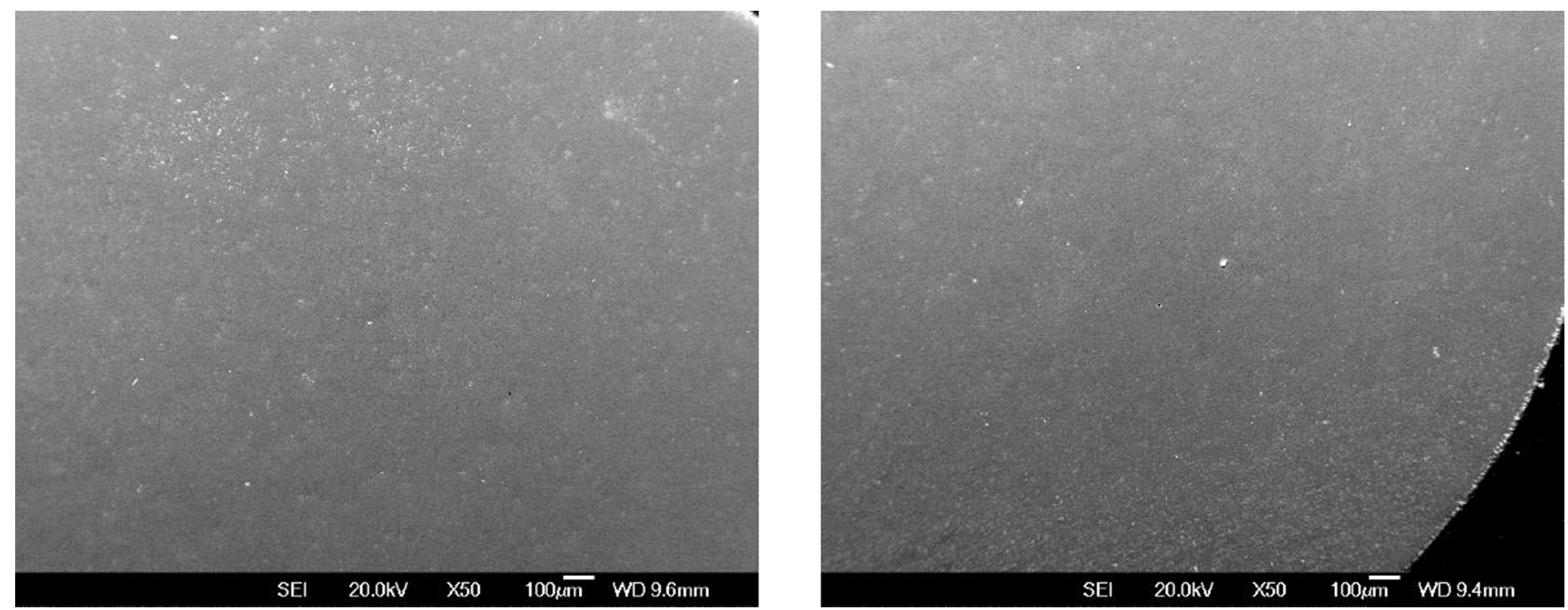

Fig. 7. SEM micrographs of formed sample, centre (left), edge (right).

Figures $3-5$ present the XRD patterns of the obtained $\mathrm{ZrO}_{2}-3 \mathrm{Y}-3 \mathrm{Ce}, \mathrm{ZrO}_{2}-3 \mathrm{Y}-6 \mathrm{Ce}$ and $\mathrm{ZrO}_{2}-3 \mathrm{Y}-9 \mathrm{Ce}$, respectively, and point out the fact that with the increase in the thermal treatment induces the temperature of the crystallite sizes to increase. Also it can be observed that there are no intermediary compounds present within the tetragonal zirconia mainly and in the monoclinic and cubical zirconia secondary.

$\mathrm{Up}$ to $800{ }^{\circ} \mathrm{C}$ in the $\mathrm{ZrO}_{2}-3 \mathrm{Y}-3 \mathrm{Ce}$ powders, it may be observed the presence of a dual phase structure with $\sim 90 \%$ tetragonal zirconia and $\sim 10 \%$ monoclinic zirconia. Over $800^{\circ} \mathrm{C}$, it can be observed an increase of the monoclinic phase concentration (which does not contain any dopant) that can be equivalent with an increase of the dopant in the tetragonal zirconia matrix, and therefore, a step-by-step transformation of it into cubical zirconia. In samples with higher $\mathrm{Ce}$ concentration $\left(\mathrm{ZrO}_{2}-3 \mathrm{Y}-6 \mathrm{Ce}\right.$ and $\mathrm{ZrO}_{2}-3 \mathrm{Y}-$ $9 \mathrm{Ce}$, respectively), it may be observed a monophasic structure (tetragonal) up to $400^{\circ} \mathrm{C}$. Above $400^{\circ} \mathrm{C}$, the behaviour is similar in terms of the presence of the cubical and monoclinic phases above $800^{\circ} \mathrm{C}$.

Figure 6 shows the morphology of the spray-dried $\mathrm{ZrO}_{2}-3 \mathrm{Y}-6 \mathrm{Ce}$ powder used in the FAST sintering process. It may be observed that powders obtained via hydrothermal process followed by spray drying are formed from spherical particles with sizes below $50 \mu \mathrm{m}$.

The bulk and tap densities of $\mathrm{ZrO}_{2}-3 \mathrm{Y}-6 \mathrm{Ce}$ spray dried powders were 1.149 and $1.675 \mathrm{~g} / \mathrm{cm}^{3}$, respectively, and they have been further used in FAST sintering process.

Figure 7 presents the SEM micrograph of FAST sintered $\mathrm{ZrO}_{2}-3 \mathrm{Y}-6 \mathrm{Ce}$. The relative density of the sample was calculated to be $99.47 \%$ under the sintering condition at $1300{ }^{\circ} \mathrm{C}$ and $125 \mathrm{MPa}$, with $25^{\circ} \mathrm{C} / \mathrm{s}$ heat rate and $120 \mathrm{~s}$ holding time. It may be observed that no open porosity exists, indicating the formation of a fully dense bulk material.

The XRD pattern of sintered pellets obtained at $1300{ }^{\circ} \mathrm{C}$ from $3 \mathrm{Y}-\mathrm{ZrO}_{2}$ powders doped with $3 \%, 6 \%$ and $9 \%$ $\mathrm{Ce}$, respectively, is presented in Figure 8. The results point out the fact that as the concentration of Ce increases such that the content of monoclinic zirconia is diminished becoming undetectable for sample doped with Ce, while the content of tetragonal phase is increasing. The XRD analysis of sintered pellets revealed that crystallite size is kept within $8-9 \mathrm{~nm}$, proving the advantages of the proposed FAST sintering process in controlling grain growth. Compared to study on the stability of yttria-doped zirconia obtained by sol-gel process described in [17], the co-doping of zirconia with $\mathrm{Ce}$ and $\mathrm{Y}$ seems to enhance the grain growth inhibition and leads to sintered compacts with fully dense tetragonal crystalline structure.

\section{Conclusions}

On the basis of the study of the effect of co-doping $3 \mathrm{~mol} . \%$ yttria-doped zirconia with 3-9 mol.\% Ce on the thermal stability of the system, it may be concluded that a material that could be fully densified by a FAST sintering process at lower temperatures, preserving its initial nanostructure, can be developed.

The original results obtained show that no intermediary compounds could be formed within the $\mathrm{ZrO}_{2}-3 \mathrm{Y}-n \mathrm{Ce}$ ( $n=3,6$ and 9 ). $\mathrm{Up}$ to $400^{\circ} \mathrm{C}$, the presence of a monophasic structure could be identified. At higher concentrations of $\mathrm{Ce}$ and higher thermal treatment temperatures, it may be observed that mainly the tetragonal zirconia is formed and secondary to the monoclinic and cubic structures. At higher temperatures, tetragonal zirconia is formed as major phase with the presence of secondary monoclinic and cubic phases, depending on the Ce content and thermal treatment temperature. Sintered compacts with densities up to $99.5 \%$ from the theoretical density were obtained starting from the $6 \% \mathrm{CeO}_{2}-3 \% \mathrm{Y}_{2} \mathrm{O}_{3}-\mathrm{ZrO}_{2}$ granulated nanostructured powders using a special field assisted (FAST) sintering process. The FAST sintering process preserves the initial nanometric grain sizes. With increasing Ce content from $3 \%$ to $9 \%$, the monoclinic phase content is diminished, and pellets with fully tetragonal structure were obtained. 


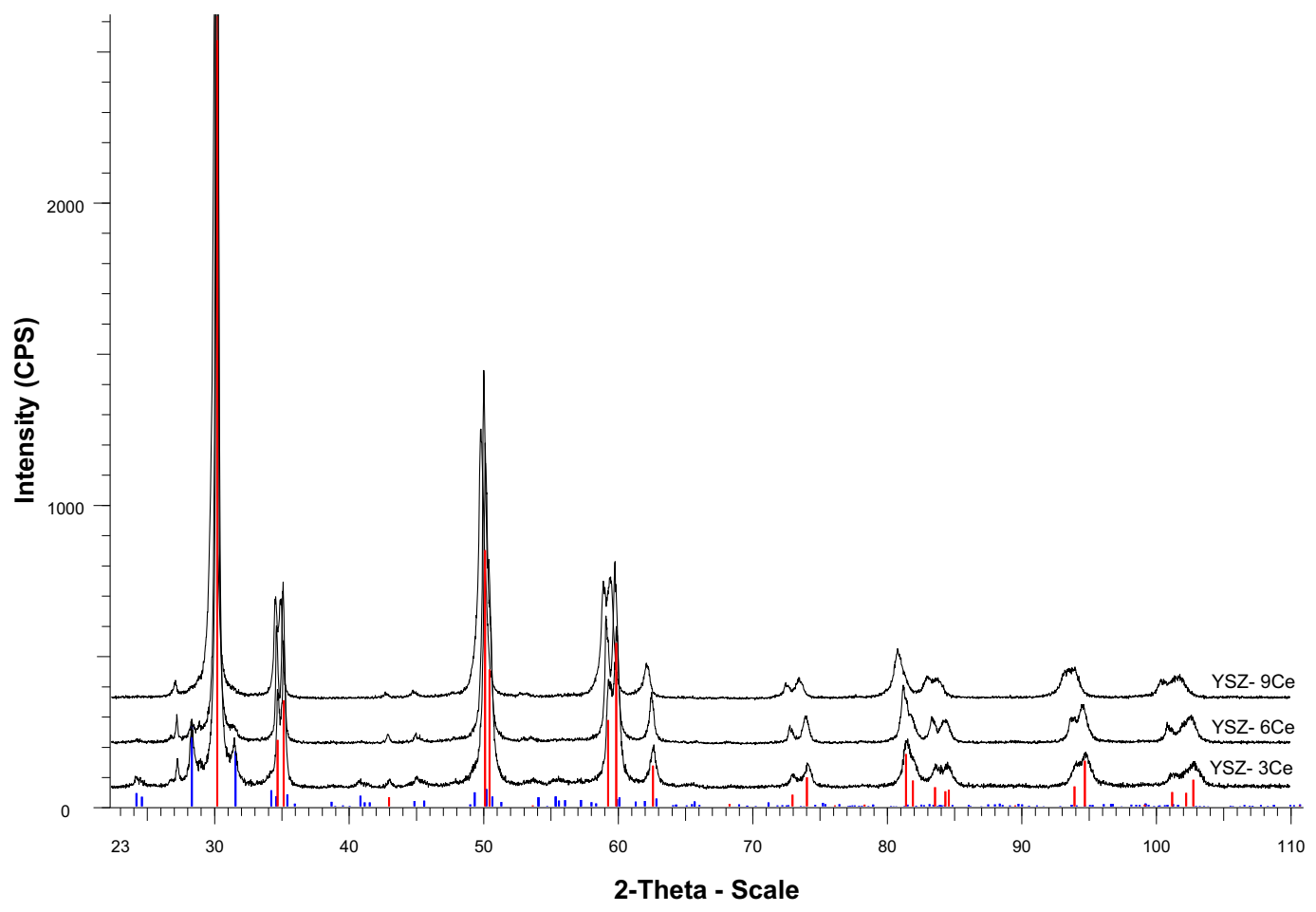

Fig. 8. XRD pattern of $\mathrm{ZrO} 2-3 \mathrm{Y}$ sintered pellets doped with $3 \%, 6 \%$ and $9 \%$ Ce, respectively.

Further studies are being conducted with a view to studying in detail the thermally induced crystallite growth kinetics which occur within the doped zirconia nanopowders with increase of the temperature.

All the authors would like to acknowledge the support provided by E.C. in the frame of FP7 Project Micro-FAST (GA 608720). Dr. R.R. Piticescu also acknowledges the support from E.C. in the frame of H2020 Grant 692216 SUPERMAT. Dr. V. Badilita and Dr. V. Dragut also acknowledge the support from Romanian Ministry for Scientific Research and Innovation in the frame of Project PN 16200402.

\section{References}

[1] K. Byrappa, M. Yoshimura, Handbook of hydrothermal technology, 2nd edn., Elsevier, 2013

[2] M. Saremi, Z. Valefi, Ceram. Int. 40(8) (2014) 13453-13459

[3] M.-J. Lee, S.-K. Hong, B.-H. Choi, H.-J. Hwang, Ceram. Int. 42(8) (2016) 10110-10115

[4] P. Cousin, R.A. Ross, Mater. Sci. Eng. A 130 (1990) 119-125

[5] C. Gionco, M.C. Paganini, M. Chiesa, S. Maurelli, S. Livraghi, E. Giamello, Appl. Catal. A: Gen. 504 (2015) 338-343
[6] W. Pyda, A. Marchlewska, M.M. Bucko, A. Pyda, Mater. Ceram. 62(3) (2010) 328-334

[7] S. Shukla, S. Seal, Int. Mater. Rev. 50(1) (2005) 1-20

[8] I.G. Tredici et al., J. Eur. Ceram. Soc. 32(2) (2012) 342-352

[9] M. Abdullah, I.W. Lenggoro, F. Iskandar, Adv. Powder Technol. 17(6) (2006) 587-611

[10] A.N. Bugrov, O.V. Almjasheva, Nanosyst.: Phys. Chem. Math. 4(6) (2013) 801-815

[11] W.S.C. de Sousa, D.M.A. Melo, J.E.C. da Silva, R.S. Nasar, M.C. Nasar, J.A. Varela, Ceramica 53 (2007) 99-103

[12] B. Ma, Y. Li, K. Su, Appl. Surf. Sci. 255 (2009) 7234-7237

[13] Y.W. Hsu, K.-H. Yanga, K.-M. Chang, S.-W. Yeh, M.-C. Wang, J. Alloys Compd. 509 (2011) 6864-6870

[14] J.-H. Lee, P.-C. Tsai, C.-L. Chang, Surf. Coat. Technol. 202 (2008) 5607-5612

[15] G. Di Girolamo, C. Blasi, M. Schioppa, L. Tapfer, Ceram. Int. 36 (2010) 961-968

[16] R.R. Piticescu, D. Millers, C. Monty, Sens. Actuators B: Chem. 109(1) (2005) 102-106

[17] W.-E. Leib, U. Vainio, R.M. Pasquarelli, J. Kus, C. Czaschke, N. Walter, R. Janssen, M. Muller, A. Schreyer, H. Weller, T. Vossmeyer, J. Colloids Interfaces 448 (2015) $582-592$

Cite this article as: Dumitru V. Dragut, Viorel Badilita, Adrian M. Motoc, Radu R. Piticescu, Jie Zhao, Hasan Hijji, Luca Conte, Thermal stability and field assisted sintering of cerium-doped YSZ ceramic nanoparticles obtained via a hydrothermal process, Manufacturing Rev. 4, 11 (2017) 